\title{
End-of-life practices in Danish ICUs: development and validation of a questionnaire
}

Hanne Irene Jensen ${ }^{1 *}$, Jette Ammentorp ${ }^{2+}{ }^{\text {, Mogens Erlandsen }}{ }^{3+}$ and Helle Ørding ${ }^{1+}$

\begin{abstract}
Background: Practices for withholding or withdrawing therapy vary according to professional, cultural and religious differences. No Danish-validated questionnaire examining withholding and withdrawing practices exists, thus the aim of this study was to develop and validate a questionnaire for surveying the views of intensive care nurses, intensivists, and primary physicians regarding collaboration and other aspects of withholding and withdrawing therapy in the ICU.
\end{abstract}

Methods: A questionnaire was developed on the basis of literature, focus group interviews with intensive care nurses and intensivists, and individual interviews with primary physicians. The questionnaire was validated in the following 3 phases: a qualitative test with 17 participants; a quantitative pilot test with 60 participants; and a survey with 776 participants. The validation process included tests for face and content validity (by interviewing participants in the qualitative part of the pilot study), reliability (by assessing the distribution of responses within the individual response categories), agreement (by conducting a test-retest, evaluated by paired analyses), known groups' validity (as a surrogate test for responsiveness, by comparing two ICUs with a known difference in end-oflife practices), floor and ceiling effect, and missing data.

Results: Face and content validity were assessed as good by the participants in the qualitative pilot test; all considered the questions relevant and none of the participants found areas lacking. Almost all response categories were used by the participants, thus demonstrating the questionnaires ability to distinguish between different respondents, agreement was fair (the average test-retest agreement for the Likert scale responses was 0.54 (weighted kappa; range, $0.25-0.73$ ), and known groups' validity was proved by finding significant differences in level of satisfaction with interdisciplinary collaboration and in experiences of withdrawal decisions being unnecessarily postponed. Floor and ceiling effect was in accordance with other questionnaires, and missing data was limited to a range of $0-7 \%$ for all questions.

Conclusions: The validation showed good and fair areas of validity of the questionnaire. The questionnaire is considered a useful tool to assess the perceptions of collaboration and other aspects of withholding and withdrawing therapy practices in Danish ICUs amongst nurses, intensivists, and primary physicians.

\section{Background}

Whether or not to withhold or withdraw therapy is a common issue in intensive care units (ICUs), as approximately $60-90 \%$ of deaths in Western ICUs occur after therapy has been withheld or withdrawn [1,2]. Withholding therapy is defined as a decision not to start or increase a life-sustaining intervention and withdrawing

\footnotetext{
* Correspondence: hanne.irene.jensen@slb.regionsyddanmark.dk

${ }^{\dagger}$ Equal contributors

'Department of Anaesthesiology, Vejle Hospital, Vejle, Denmark

Full list of author information is available at the end of the article
}

therapy as a decision to actively stop a life-sustaining intervention presently being given [2].

The parties involved in the decisions might not assess the situation in the same way [3-5]; among the healthcare professionals, nurses normally are the first to find therapy futile [4-6]. Practices for withholding or withdrawing therapy also vary according to cultural and religious differences [2,7-9]. In a joint European study examining end-of-life practices in ICUs [2], results from two Danish university affiliated ICUs were included [10]. Apart from this study, limited research on withholding or withdrawing therapy in Danish ICUs has been published.

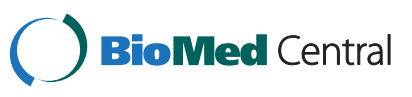


A questionnaire survey was designed to determine the views of Danish intensive care nurses, intensivists, and primary physicians on withholding and withdrawal of therapy practices. As no validated Danish questionnaire exists, the aim of this study was to develop and validate a questionnaire for surveying the views of intensive care nurses, intensivists, and primary physicians regarding collaboration and other aspects of withholding and withdrawing therapy in the ICU.

\section{Methods}

\section{Development of the questionnaire}

\section{Interviews}

On the basis of the extant literature, a semi-structured interview guide was developed focusing on the following three main areas: 1) perceptions of the conditions which could/should induce considerations about withholding or withdrawing therapy in the ICU; 2) the challenges which were experienced regarding withholding or withdrawing therapy; and 3) the perception of what characterizes "good" and "poor" decision processes regarding withdrawal of therapy. In order to ensure that all issues were identified which were assessed as important by the participants, the participants were finally asked: "Are there other important areas regarding end-of-life decisions we have not talked about?"

Four focus group interviews, two with nurses and two with intensivists, were conducted (between 4 and 6 participants in each group; 21 in total). The participants were randomly selected between all staff from 2 ICUs from different hospitals in the study region (ICU A and B), with staff experience taken into account, so all groups consisted of staff with short, medium, and long experiences from the ICU. The nurses were all females, whereas there were 4 female and 6 male intensivists. The intensivists included anaesthesiologists with the ICU as the main workplace and anaesthesiologists who only worked in the ICU on shifts.

From the specialities with the largest percentage of patients admitted to the ICU, primary physicians providing care for patients in the hospital prior to ICU transfer were included. For each ICU, four primary physicians were approached. The physicians were identified by the head of department, the senior secretary, or by the ICU. All primary physicians ( 4 females and 4 males) agreed to participate in a semi-structured, individual interview based on the same interview guide.

Both focus groups and individual interviews were audio-taped, verbally-transcribed, analysed, and the main themes were extracted $[11,12]$. The themes included collaborative issues, changing of withholding decisions which were already made, and unnecessary postponement of withdrawing therapy decisions. All three groups of staff agreed that the main challenge was the process of making a decision of withholding or withdrawing therapy, whereas care given to patients and relatives in whom therapy was withdrawn was found to be easy and good.

\section{Questionnaire}

Based on the extant literature, focus groups, and individual interviews, a questionnaire was developed in accordance with the recommendations for questionnaire design by $\mathrm{A}$. Bowling [13]. In the initial process, questions were formulated, assessed, refined, or rejected in collaboration with a team of teachers in questionnaire methodology, quality managers, and intensive care nurses and physicians.

The pilot questionnaire consisted of 39 questions. Apart from questions on background characteristics, the questionnaire had 4 questions regarding reasons for withholding or withdrawing therapy, 2 questions on the process of admitting patients to the ICU, 12 questions on the decision making process regarding withholding or withdrawing therapy, 7 questions on collaboration, 3 questions on documentation, and 4 questions on care for patients and relatives in whom therapy had been withdrawn.

Although the questions were grouped by main themes, the questions were all single-item questions (each question covering a specific area with no automatic correlation expected with other question). Therefore, none of the questions permitted sum-scores [14].

The questions consisted of two types. The first type of question had responses on two different, four- or fivepoint Likert scales ("very satisfactory", "satisfactory", "less satisfactory", and "unsatisfactory", or "always", "often", "sometimes", "rarely", and "never", both with a "don't know" option). The second type of question was mostly used to explain reasons for a type 1 question ("If you experience that this is happening, what are the reasons in your opinion?") or to state recommendations, and these questions had multiple response options. For most of the questions, comments could be added.

The questionnaires were identical for the three staff groups, with the exception of a few questions about background characteristics, and a question for the primary physicians about how often they had patients they wanted to transfer to the ICU, but who were refused by the intensivists.

\section{Validation process}

The validation process consisted of the following 3 phases: a qualitative test with 17 participants from ICU $A$ and B (from different hospitals within the study region); a quantitative pilot test with 60 participants from ICU I and II (from different hospitals outside the study region); and a survey with 776 participants from 10 ICUs (from all 7 hospitals in the study region except for primary physicians who came from only 2 of the ICUs) (Figure 1). 
The aim of the validation process was to test for:

1. Face validity (does the questionnaire "look like" it is going to measure what it is supposed to measure?) and content validity (do the questions reflect areas that are essential/useful to clarify the purpose of the study?) [15]. Both face and content validity were examined by interviewing pilot study participants after they had responded to the questionnaire. The participants were asked about their general perception of the questionnaire, how they had understood the individual questions, if areas of importance in regard to the subject of the questionnaire were missing, and if any of the questions in their opinion were irrelevant.

2. Reproducibility, which includes reliability and agreement [15]. Reliability is here understood as the questionnaires ability to distinguish between different respondents. If all survey participants respond identically to the individual items, reliability will be low. Reliability is here examined by looking at the distribution of responses. Agreement is understood as consistency in a test-retest, and it is in this study examined with a weighted kappa analysis of responses provided by the same participants within a two week period.

3. Responsiveness, which means the questionnaires ability to detect improvements [15]. As no intervention was tested in the pilot study, known groups' validity was used as a surrogate concept. Whereas ICU I had no special focus on end-of-life practices, ICU II had focused intensively on end-oflife issues and had developed and implemented guidelines for withdrawal of therapy. Known groups' validity was tested based on the hypothesis that ICU II would be more satisfied with collaboration, less frequently experience withdrawing of therapy being unnecessarily postponed, and find care of dying patients more satisfactory compared to ICU I. We hypothesised that if the instrument's ability to detect a difference between the two ICUs was high, the instrument would presumably also be able detect improvements within the individual ICU.

4. Floor/ceiling effect. A high floor and/or ceiling effect may reduce reliability and prevent the ability of the instrument to detect improvement because substantial samples of respondents have already reached the lowest/highest score [15].

5. Missing data. The data was analysed to assess whether or not specific questions had a high percentage of missing data or the percentage of missing data increased in the last questions, indicating that the questionnaire was too long.

\section{Survey \\ Qualitative pilot test}

The questionnaire was first tested qualitatively for face and content validity. The test was conducted with 11 nurses and 5 intensivists from ICU A and B, and 1 primary physician affiliated with ICU A.

\section{Quantitative pilot test}

The questionnaire was adjusted based on results from the qualitative pilot study, then tested quantitatively in 2 ICUs from a region not part of the main study. In ICU I, 20 nurses and 10 physicians received the questionnaire

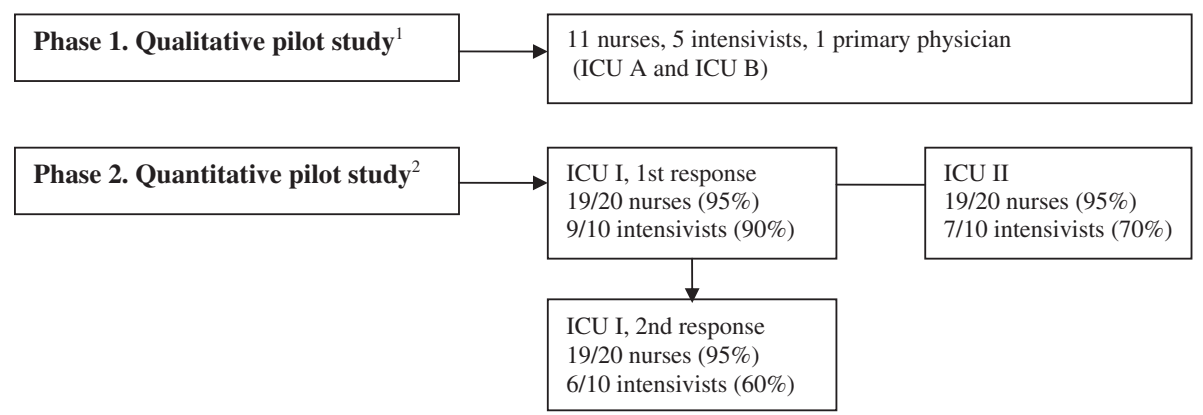

\begin{tabular}{|l|l|}
\hline Phase 3. Main survey $^{3}$ & $\rightarrow \begin{array}{l}423 / 495 \text { nurses }(86 \%) \\
104 / 135 \text { intensivists }(77 \%) \\
122 / 146 \text { primary physicians }(84 \%)\end{array}$ \\
\hline
\end{tabular}

\footnotetext{
1. Conducted in 2 ICUs (ICU A and ICU B) from different hospitals within the study region

2. Conducted in 2 ICUs (ICU I and ICU II) from different hospitals outside the study region

3. Conducted in 10 ICUs from 7 different hospitals in the study region (for nurses and intensivists and in 2 ICUs for primary physicians)
}

Figure 1 Participants and response rates in the validation study and the main survey. 
twice with a 2-week interval. In ICU II another 20 nurses and 10 physicians received the questionnaire once. In both ICUs, all participants were selected by the charge nurse. The participants were asked to comment on relevance and phrasing of questions.

\section{Main survey}

After the pilot study, the questionnaire was used in a survey including 495 nurses and 135 intensivists from 10 ICUs and 146 primary physicians from 2 ICUs [16]. Nurses and intensivists who had been in the ICU for at least 5 months and primary physicians who had attended their patients in the ICU during the last 5 months were eligible for participation in the study. All participants received the questionnaire at their place of employment. Two reminders were sent. The study was conducted in April-June 2010 for nurses and intensivists and in June-August 2010 for primary physicians. Results from the main survey, including a copy of the questionnaire as a supplemental file, are published [16].

\section{Data analysis}

All data were double-entered in EpiData (version 3.1), and statistical analyses were performed using STATA 10.1. A chi-square test and Mann-Whitney $U$ test were used to compare background characteristics. Descriptive statistics were used to examine missing data, and the floor and ceiling effect. The weighted kappa and Wilcoxon signed-ranked test were used to test for agreement [17]. Known groups' validity was tested by a comparison between ICU I and ICU II, using the Mann-Whitney $U$ test. The level of significance was set at a $\mathrm{p}<0.05$.

Interview data and questionnaire comments were analysed using the meaning condensating method introduced by Kvale [11] and content analysis [12].

\section{Ethics}

According to Danish law, the study did not require permission from the Regional Ethics Committee, as confirmed by the Regional Ethics Committee. Permission to obtain and store code lists of staff was granted from The Danish Data Protection Agency (j.o. 2009-41-3189). All Heads of Departments gave permission for their staff to take part in the survey. All participants were informed in writing of the purpose of the study, that participation was voluntary, and that responses were anonymous.

\section{Results}

\section{Participants}

As shown in Figure 1, response rates were 95\% (38/40) for nurses and $80 \%(16 / 20)$ for intensivists in the quantitative pilot study.
Table 1 presents background information of the participants. There were no significant differences between the two ICUs.

In the main survey, the overall response rate was $84 \%$ (649/776; 86\% [423/495] for nurses, 77\% [104/135] for intensivists, and $84 \%$ [122/146] for primary physicians). Background information of the participants in the main survey is described elsewhere [16].

\section{Face and content validity}

All participants in the qualitative and quantitative pilot test considered the questions relevant and none of the participants found areas lacking; likewise, the participants had understood the questions as expected. Minor adjustments to phrasing and response options in multiple response questions were pointed out, and the questionnaire was changed accordingly.

\section{Comments}

Approximately one-half of the respondents from the pilot study and the regional survey had used the opportunity to write comments, adding to more than 20,000 words. The comments elaborated the responses and thus elucidated how the questions had been understood. The comments indicated that the questions had been understood and responded to as expected. The exceptions were two questions in which a few respondents in the quantitative pilot test had misunderstood the conditions of the questions. In the main survey, the explanation was highlighted and a definition was added.

Examples of comments were:

To the question "In your experience, are there patients admitted to the ICU who in your opinion should not have been offered intensive therapy?"

Table 1 Background characteristics of participants in the quantitative pilot study

\begin{tabular}{|c|c|c|c|c|c|}
\hline & \multicolumn{2}{|c|}{$|C U|^{1}$} & \multicolumn{2}{|c|}{$\mathrm{ICU} \mathrm{II}^{1}$} & \multirow[t]{2}{*}{$p^{1}$} \\
\hline & $\mathbf{n}$ & $\%$ & $\mathrm{n}$ & $\%$ & \\
\hline Gender & 28 & & 26 & & 0.43 \\
\hline Male & 5 & (17.9) & 7 & (26.9) & \\
\hline Female & 23 & $(82.1)$ & 19 & $(73.1)$ & \\
\hline Profession & 28 & & 26 & & 0.68 \\
\hline Physician & 9 & (32.1) & 7 & $(26.9)$ & \\
\hline Nurse & 19 & $(67.9)$ & 19 & $(73.1)$ & \\
\hline Age groups (years) & 28 & & 26 & & 0.43 \\
\hline$<30$ & 2 & $(7.1)$ & 6 & $(23.1)$ & \\
\hline$\geq 30-<40$ & 8 & $(28.6)$ & 6 & $(23.1)$ & \\
\hline$\geq 40-<50$ & 12 & $(42.9)$ & 8 & $(30.8)$ & \\
\hline$\geq 50$ & 6 & $(21.4)$ & 6 & $(23.1)$ & \\
\hline
\end{tabular}

1. ICUs from two hospitals outside the main study region.

2. Chi-square test was used for "Gender" and "Profession."

Mann-Whitney $U$ test was used for "Age groups." 
"A number of our intensivists find it hard to "say no" to the primary physicians, even though the patient does not completely fulfill the admission criteria" (nurse, responded "very often")

To the question: "Should the nurses be involved in the decision-making process regarding withholding or withdrawing therapy?"

"Nurses have no background for assessing it professionally" (primary physician, responded "never")

To the question: "If it is your experience that decisions are unnecessarily postponed, what are the reasons in your opinion?"

"Perhaps more uncertainty.... It is a hard and often definitive decision, and the patient's condition and changes in this can be hard to predict" (intensivist, ticked "Fear of having to make decisions like these")

\section{Reliability}

The responses showed variations. Almost all response categories were used in the quantitative pilot test and all response categories were used in the main survey, except one question in which "always" was not used, four questions in which "never" was not used, and two questions in which "unsatisfactory" and "very unsatisfactory" were not used.

\section{Agreement}

The average test-retest agreement for the Likert scale responses was 0.54 (weighted kappa; range, 0.25-0.73). A significant difference was found for the following question: "satisfaction with collaboration," $p=0.003$ (participants were less satisfied in the re-test). Otherwise, no significant difference was found between the test and retest (average, $\mathrm{p}=0.35$; range, $0.06-1.00$ ). A mean of $82 \%$ (range, 50\%-100\%) of those who had changed responses from test to retest within the Likert scale had moved only one "step" up or down the scale. Additionally, a mean of $5 \%$ (range, $0 \%-12 \%$ ) had moved either to or from a "do not know" response. For multiple response questions, an average of $81 \%$ (range, 60-100\%) of responses was identical between the test and retest.

\section{Known groups' validity}

Table 2 presents comparisons between responses from ICU I and ICU II on three main questions in which a difference would be expected due to ICU II having worked with guidelines for withdrawing therapy. In ICU II, the healthcare professionals were significantly more satisfied with collaboration and less often experienced decisions regarding withdrawal of life-sustaining therapy
Table 2 Comparison between ICU I and ICU II on main questions regarding withholding or withdrawing therapy practices

\begin{tabular}{|c|c|c|c|c|c|}
\hline & \multicolumn{2}{|c|}{ ICU I' } & \multicolumn{2}{|c|}{ ICU II } & \multirow[t]{2}{*}{$\mathbf{p}^{3}$} \\
\hline & $\overline{n^{2}}$ & $\%$ & $\overline{n^{2}}$ & $\%$ & \\
\hline $\begin{array}{l}\text { Decisions regarding } \\
\text { withdrawal of therapy are } \\
\text { unnecessarily postponed }\end{array}$ & 28 & & 25 & & $<0.001$ \\
\hline Very often & 1 & (3.6) & 0 & (0) & \\
\hline Often & 10 & $(35.7)$ & 2 & $(8.0)$ & \\
\hline Sometimes & 15 & (53.6) & 11 & $(44.0)$ & \\
\hline Rarely & 2 & $(7.1)$ & 10 & $(40.0)$ & \\
\hline Never & 0 & (0) & 2 & $(8.0)$ & \\
\hline $\begin{array}{l}\text { General satisfaction } \\
\text { with collaboration }\end{array}$ & 28 & & 26 & & $<0.001$ \\
\hline Extrememly satisfactory & 0 & (0) & 4 & $(15.4)$ & \\
\hline Very satisfactory & 5 & $(17.9)$ & 13 & $(50.0)$ & \\
\hline Satisfactory & 12 & $(42.9)$ & 7 & (26.9) & \\
\hline Less satisfactory & 9 & $(32.1)$ & 2 & $(7.7)$ & \\
\hline Unsatisfactory & 2 & $(7.1)$ & 0 & (0) & \\
\hline Care for dying patients & 26 & & 24 & & 0.07 \\
\hline Extrememly satisfactory & 11 & $(42.3)$ & 16 & $(66.7)$ & \\
\hline Very satisfactory & 14 & $(53.9)$ & 8 & (33.3) & \\
\hline Satisfactory & 1 & (3.9) & 0 & (0) & \\
\hline
\end{tabular}

1. ICUs from two hospitals outside the main study region.

2. Different $\mathrm{n}$ due to "don't know" responses and missing data.

3. Mann-Whitney $U$ test.

being unnecessarily postponed compared to ICU I. A non-significant difference was found in the perception of the care provided for dying patients.

\section{Floor and ceiling effect}

The majority of participants in the qualitative pilot test considered the Likert scales too restricted. The floor/ ceiling control showed that $50 \%$ of the questions had a ceiling effect (responses in the highest category; range, $19-94 \%)$ higher than the recommended $15 \%$ as a maximum $[15,18]$, and $25 \%$ of the questions had $>50 \%$ of the responses in the highest category. No questions exceeded $15 \%$ in the floor effect. Therefore, the Likert scales were extended from four/five to six response options (e.g., always, very often, often, sometimes, rarely, and never). In the quantitative pilot study, the floor/ceiling effect was reduced, as follows: $55 \%$ of the questions had a ceiling effect of $>15 \%$ (range, $17-57 \%$ ) with $10 \%$ of the questions having $>50 \%$ in the highest response category. No questions exceeded $15 \%$ in the floor effect.

The extended scale with the six response options was also used in the main survey, and the ceiling control showed $45 \%$ of the questions had $>15 \%$ in the highest category (range, 23-60\%); $10 \%$ of the questions had > $50 \%$ in the highest category. No questions exceeded $15 \%$ in the floor effect. 


\section{Missing data}

In the pilot study, missing data for all questions ranged from 0 to $7 \%$, and the last 5 questions had $4 \%$ missing data. In the main survey, missing data ranged from 0 to $5 \%$. The last 5 questions had 3\% missing data.

\section{Discussion}

This study describes a validation process of a newly developed questionnaire.

The test-retest results were only fair [14,17], which may be due to a lack of stability of the instrument. However, the test-retest results may also be due to the small test-retest sample (which increases the statistical error on kappa, and reduces power on the Wilcoxon signedrank test) and to the fact that many of the questions relate to experiences and attitudes regarding end-of-life issues which may be modified during a 2-week period of thinking about the issues. The changes from test to retest were mostly one step up or down the scale. Even with the small sample there was a significant difference between ICU I and ICU II, which indicates both that the questionnaire is able to detect changes, but also that the stability of the instrument is acceptable.

In the quantitative pilot test and main survey, the ceiling effect was reduced (range, 0-57/60\%) compared to the qualitative pilot study (range, $0-94 \%$ ). The range is consistent with well-known instruments [18], although it is not in agreement with the recommendations in the literature [15]. The questions with the highest ceiling effect were mainly questions regarding whether or not patients (if possible), relatives, primary physicians, and nurses should be or are involved in the decision process. The Danish law on patients' rights makes it compulsory to discuss withholding or withdrawing therapy with a competent patient, and practice recommendations for withholding or withdrawing therapy state that decisions should be multidisciplinary [19-21]. Consequently, a high ceiling effect for these specific questions is desirable. The two other questions with the highest ceiling effect were questions regarding the quality of care for patients and relatives in whom therapy was withdrawn; areas the pre-survey interviewees had pointed out already had excellent quality. Even with the high ceiling effect, the hypothesis regarding staff from ICU II being more satisfied with withholding and withdrawing therapy practices was confirmed.

No specific questions had $>7 \%$ missing data, and the percentage of missing data did not increase towards the end, indicating that the questionnaire had an acceptable length.

There may well be other, unknown factors within the ICUs which could confound the differences identified in this study between ICU I and ICU II. Nevertheless, despite the small sample size significant differences were found in specific end-of-life areas where focus on end-of-life issues and guidelines for withdrawing lifesustaining therapy would be expected to have an impact. It is therefore likely that the guidelines and the general focus on end-of- life issues are major contributors to the differences between the ICUs. As such, we also believe that it may be plausible that the instrument will be able to detect improvements within the individual ICU (responsiveness). However, this needs to be tested in further research.

With respect to construct validity, understood as the extent to which an instrument measures the expected concept [15], none of the questions were indirect (e.g., a question regarding frame of mind is supposed to elucidate the level of depression). This increases the chance of the instrument actually measuring the construct the instrument is expected to measure. However, it also reduces the statistical possibilities to validate the instrument, as e.g. factor analysis based on multiitems (and sum scores) [22] is not applicable. The comments added by the respondents indicated that the questions had been understood and responded to as expected. Conducting surveys among healthcare professionals involve a fairly homogeneous group to whom end-of-life issues and concepts are well known; this also increases the chance of the instrument measuring the expected concepts.

Tests for internal consistency (the extent to which different items within the questionnaire are correlated) and criterion validity (the extent to which the instrument measures the expected concept) may also be conducted when validating questionnaire instruments [14,15,23,24]. However, this was not applicable for this instrument as it consists of single-item questions and because there is no gold standard to test the correlation against [15].

Another weakness of the validation study was the small sample size of the quantitative pilot study; it both increased the statistical error in the test-retest analysis and prevented extensive sub-analyses in the comparison between the two ICUs.

Knowledge about withholding and withdrawing therapy practices in the ICUs is important to improve practice, and a valid questionnaire survey will assist in detecting the issues where improvements are necessary. Results from the main survey were usable in both describing "state of the art" and identifying areas for improvement [16].

The validation process and the main survey were conducted using the Danish version of the questionnaire. Subsequently, the questionnaire was translated into English by the authors and the translation was corrected by a scientific English language company. As practices for withholding or withdrawing therapy vary according to cultural and religious differences, the questionnaire is 
not automatically transferable to other countries. However, the questionnaire may be either adjusted to national conditions or be useful as inspiration for development of national questionnaires.

\section{Conclusions}

The tests showed both good and moderate areas of validity of the questionnaire. The questionnaire is considered a useful tool to assess perceptions of collaboration and other aspects of withholding and withdrawing therapy practices in Danish ICUs amongst nurses, intensivists, and primary physicians.

\section{Competing interests}

The authors declare that they have no competing interests.

\section{Authors' contributions}

HIJ designed the study, collected and analysed the data, and drafted the manuscript. JA and $H \varnothing$ participated in designing the study and supervised data collection and analyses. ME participated in analysing the data. All authors read and approved the final manuscript.

\section{Acknowledgements}

The authors thank all staff for taking part in the study. HIJ was supported by The Region of Southern Denmark, Lillebaelt Hospital, Denmark, and the philanthropic foundation TrygFonden, Denmark None of the funding bodies had any role in designing the study, colleting or analysing data, or in writing and submitting the manuscript.

\section{Author details}

${ }^{1}$ Department of Anaesthesiology, Vejle Hospital, Vejle, Denmark. ${ }^{2}$ Health Services Research Unit, Lillebaelt Hospital/IRS University of Southern, Kolding, Denmark. ${ }^{3}$ Department of Biostatistics, Aarhus University, Aarhus, Denmark.

Received: 28 September 2011 Accepted: 16 July 2012

Published: 1 August 2012

\section{References}

1. Prendergast TJ, Luce JM: Increasing incidence of withholding and withdrawal of life support from the critically ill. Am J Respir Crit Care Med 1997, 155:15-20.

2. Sprung $\mathrm{CL}$, Cohen $\mathrm{SL}$, Sjokvist $\mathrm{P}$, Baras $\mathrm{M}$, Bulow HH, Hovilehto S, Ledoux D, Lippert A, Maia P, Phelan D, Schobersberger W, Wennberg E, Woodcock T: End-of-life practices in European intensive care units: the Ethicus Study. JAMA 2003, 290:790-797.

3. Cassell J, Buchman TG, Streat S, Stewart RM: Surgeons, intensivists, and the covenant of care: administrative models and values affecting care at the end of life-Updated. Crit Care Med 2003, 31:1551-1557.

4. Breen CM, Abernethy AP, Abbott KH, Tulsky JA: Conflict associated with decisions to limit life-sustaining treatment in intensive care units. J Gen Intern Med 2001, 16:283-289.

5. Ferrand E, Lemaire F, Regnier B, Kuteifan K, Badet M, Asfar P, Jaber S, Chagnon JL, Renault A, Robert R, Pochard F, Herve C, Brun-Buisson C, Duvaldestin P: Discrepancies between perceptions by physicians and nursing staff of intensive care unit end-of-life decisions. Am J Respir Crit Care Med 2003, 167:1310-1315.

6. Heland M: Fruitful or futile: intensive care nurses' experiences and perceptions of medical futility. Aust Crit Care 2006, 19:25-31.

7. Sprung CL, Maia P, Bulow HH, Ricou B, Armaganidis A, Baras M, Wennberg E, Reinhart K, Cohen SL, Fries DR, Nakos G, Thijs LG: The importance of religious affiliation and culture on end-of-life decisions in European intensive care units. Intensive Care Med 2007, 33:1732-1739.

8. Moselli NM, Debernardi F, Piovano F: Forgoing life sustaining treatments: differences and similarities between North America and Europe. Acta Anaesthesio/ Scand 2006, 50:1177-1186.

9. Baggs JG, Norton SA, Schmitt MH, Dombeck MT, Sellers CR, Quinn JR: Intensive care unit cultures and end-of-life decision making. J Crit Care 2007, 22:159-168.
10. Bulow HH, Lippert A, Sprung C, Cohen MB, Sjokvist P, Baras M, Hovilehto S, Ledoux D, Maia P, Phelan D, Schobersberger W, Wennberg E, Woodcock T: End-of-life practices in European intensive care units [in Danish]. Ugeskr Laeger 2005, 167:1522-1525.

11. Kvale S: Interviews. Sage Publication: An introduction to qualitative research interviewing; 1996.

12. Graneheim UH, Lundman B: Qualitative content analysis in nursing research: concepts, procedures and measures to achieve trustworthiness. Nurse Educ Today 2004, 24:105-112.

13. Bowling A: Questionnaire design. In Research Methods in Health. Investing Health and Health Services. 3rd edition. Buckingham: Open University Press; 2009:299-337.

14. Streiner DL, Norman GR: Health measurement scales. A practical guide to their development and use. 4th edition. Oxford: Oxford University Press; 2008.

15. Terwee CB, Bot SDM, de Boer MR, van der Windt DAWN, Knol DL, Dekker J, Bouter LM, de Vet HCW: Quality criteria were proposed for measurement properties of health status questionnaires. J Clin Epidemiol 2007, 60:34-42.

16. Jensen HI, Ammentorp J, Erlandsen M, Ording H: Withholding or withdrawing therapy in intensive care units: an analysis of collaboration among healthcare professionals. Intensive Care Med 2011, 37:1696-1705.

17. Kirkwood BR, Sterne JAC: Essential Medical Statistics. Secondth edition. Massachusetts: Blackwell Science, Inc.; 1998.

18. McHorney CA, Tarlov AR: Individual-patient monitoring in clinical practice: are available health status surveys adequate? Qual Life Res 1995, 4:293-307.

19. Thompson BT, Cox PN, Antonelli M, Carlet JM, Cassell J, Hill NS, Hinds CJ, Pimentel JM, Reinhart K, Thijs LG: Challenges in end-of-life care in the ICU: statement of the 5th International Consensus Conference in Critical Care: Brussels, Belgium, April 2003: executive summary. Crit Care Med 2004, 32:1781-1784.

20. Baggs JG, Norton SA, Schmitt MH, Sellers CR: The dying patient in the ICU: role of the interdisciplinary team. Crit Care Clin 2004, 20:525-540.

21. Curtis JR, Vincent JL: Ethics and end-of-life care for adults in the intensive care unit. Lancet 2010, 376:1347-1353.

22. Baggs JG: Development of an instrument to measure collaboration and satisfaction about care decisions. J Adv Nurs 1994, 20:176-182.

23. Engelberg RA, Downey L, Wenrich MD, Carline JD, Silvestri GA, Dotolo D, Nielsen EL, Curtis JR: Measuring the quality of end-of-life care. J Pain Symptom Manage 2010, 39:951-971.

24. Zomorodi MF, Lynn MR: Instrument development measuring critical care nurses' attitudes and behaviors with end-of-life care. Nurs Res 2010, 59:234-240.

doi:10.1186/1471-2253-12-16

Cite this article as: Jensen et al:: End-of-life practices in Danish ICUs: development and validation of a questionnaire. BMC Anesthesiology 2012 12:16.

\section{Submit your next manuscript to BioMed Central and take full advantage of:}

- Convenient online submission

- Thorough peer review

- No space constraints or color figure charges

- Immediate publication on acceptance

- Inclusion in PubMed, CAS, Scopus and Google Scholar

- Research which is freely available for redistribution 